\title{
Revisión histórica de la bibliografía gimnástico-deportiva impresa en Barcelona (s. XIX-1910)
}

\author{
Xavier Torrebadella Flix \\ Universidad Autónoma de Barcelona - UAB, España
}

ARTICLE

\begin{abstract}
Resumen
En este artículo se presenta un repertorio bibliográfico gimnástico-deportivo de 67 obras impresas en Barcelona entre 1820-1910. El trabajo contiene además un estudio bio-bibliográfico genérico y contextualizado de las obras. La localización de las fuentes documentales tienen como punto de partida los estudios recientes del autor. Con ello se pretende contribuir a la organización de la memoria social y a la divulgación del patrimonio documental histórico de la educación física y el deporte. El análisis crítico y contextual de este repertorio pone de relieve el protagonismo que ejerció Barcelona en la difusión del asociacionismo deportivo y de la emergente literatura que acompañó este proceso.
\end{abstract}

Palabras clave

Repertorio bibliográfico ; Historia del deporte ; Educación física ; Barcelona

Historical review of the printed bibliography on gymnastics-sport in Barcelona (19th century1910)

\begin{abstract}
This article presents a bibliographical repertoire of gymnastics-sport consisting of 67 works printed in Barcelona from 18201910. The work also contains a generic bio-bibliographic and contextualised study of the publications. The documentary sources were localised using other recent works by the author. The aim is to contribute to the organisation of social memory and the dissemination of the historical documentary heritage of physical education and sport. The critical and contextual analysis of this repertory highlights the centrality of Barcelona in the diffusion of the existence of sport associations and the emerging literature accompanying that process.
\end{abstract}

Keywords

Bibliographical repertoire ; History of sport ; Physical education ; Barcelona

\section{Introducción}

La documentación, como citaba Rufino Blanco (1927), discípulo de Menéndez Pelayo (Blanco, 1925; Menéndez, 1876), es la base de toda erudición y con ella los científicos o estudiosos de un tema muy pronto podrán alcanzar las metas deseadas. Esta certeza, que no debería traspasar el sentido de lo común, todavía sigue siendo un escollo para muchas investigaciones, carentes de tiempo o de paciencia para abordar una mínima revisión bibliográfica de rigor (Torrebadella, 2014e). Las revisiones bibliográficas son necesarias para presentar buenos estudios, pero antes también son aún de mayor importancia los repertorios bibliográficos, los catálogos descriptivos y temáticos, y otras fuentes de conocimiento que son las bases que iluminan el camino de las investigaciones y de la ciencia.

Hoy la educación física, materia con muy pocos años de existencia en el ámbito de las ciencias pedagógicas, tiene poca singladura historicista (Aquesolo, 2000). Como materia de erudición, la educación física y el deporte poseen un corpus académico, hasta no hace mucho, muy poco valorado desde las instancias de las ciencias de 
la documentación y, es por esta razón, que aún tiene que rescatar abundantes sellos de identidad de su pasado. Descubrir documentos, archivos y textos es todavía una aventurera tarea de la arqueología que suscita la pasión de los documentalistas y de algunos bibliógrafos. Asimismo en las llamadas ciencias sociales del deporte, que presentan una crítica postmoderna, el reto interdisciplinar académico, no acredita en España, a diferencia de otros países, apenas una intención historicista y revisionista.

En estos últimos años, mi principal línea de investigación se ha centrado en torno a los estudios documentales de la educación física y el deporte entre 1800 y 1939. Estudios de revisión bibliográfica, de análisis crítico o descriptivos han puesto ante la comunidad científica una amplia y variada muestra de referencias para el conocimiento (Torrebadella, 2011a, 2011b, 2011c; 2012a, 2012b, 2013a; Torrebadella y Olivera, 2012, 2013; Torrebadella y Nomdedeu, 2014, 2015). Conocedores de la tarea que hemos emprendido, nuestra meta, como considera la profesora Díez Ménguez (2000), no tiene fin.

Para la organización de la memoria social, la divulgación del patrimonio documental es una necesidad de urgencia. Si este patrimonio ya ocupa una situación marginal en estos momentos de cénit de las nuevas tecnologías y de avances en la archivística, también lo es en la catalogación histórica, que cada vez representa una menor presencia de los estudios bibliográficos. Por esta razón coincidimos con otros autores (Aquesolo, 2000; Berasategui, 2008; Pastor, 1995, 2003; Vilanou y Martínez, 1995) en alumbrar esta frágil pero fundamental especialidad en torno a la documentación y las fuentes del conocimiento histórico de la educación física y el deporte. No obstante, surge aquí el problema todavía no resuelto de la rigurosa indización de las obras (Martins, 2002).

La pasión bibliófila está fundamentada por la arqueología versus el libro perdido u olvidado; razón obvia para alcanzar nuestro objeto de estudio: el de contribuir a la construcción del conocimiento. Sea pues, desde las ciencias de la Documentación e Información presentar un instrumento para facilitar el análisis de contenido de la indización académica de las obras (Pinto, 1989, 2002).

Ciertamente la falta y recuperación de catálogos retrospectivos que alude Gallego (2005) es en nuestro ámbito de estudio, como en el de tantos otros, una importante laguna en el empeño de cimentar el conocimiento.

El presente estudio se centra en la bibliografía gimnástica-deportiva decimonónica y de la primera década del siglo XX impresa en Barcelona. Ubicamos, pues esta acotación territorial y temporal en Barcelona por su indiscutible razón de ser cuna del asociacionismo deportivo en España y por la potencia que irradió a partir de las numerosas iniciativas (Torrebadella, 2012c, 2014d, 2015; Torrebadella-Flix, Olivera-Betrán y M-Bou, 2015; Torrebadella y Arrechea, 2015). Este suceso venía acompañado de una floreciente transformación industrial, económica y urbana que desde el último cuarto del siglo XIX se fundía con los discursos regeneracionistas finiseculares y el movimiento cultural del modernismo de principios del siglo XX y su dimensión social en la Belle époque.

La parte heurística ha venido facilitada por los propios repertorios históricos de estudios anteriores (Torrebadella, 2009, 2011b), principalmente confeccionados a través del Catalogo del Gimnasio de Colón de Amadeo Llaverias (1935), la Bibliografía y material de enseñanza. Educación física e higiene escolar del Museo Pedagógico Nacional (1915) y la Bibliografía General de la Educación Física de Rufino Blanco (1927). Asimismo hemos sacado fruto de la digitalización de las hemerotecas de la prensa histórica para adquirir informaciones en cuanto al objeto de estudio.

Presentamos pues una parte de resultados y discusión, o análisis bio-bibliográfico contextualizado, que se completa con el correspondiente repertorio bibliográfico de 67 obras impresas en Barcelona entre 1820 y 1910 (organización cronológico-nominal por décadas). A modo de conclusión, y a partir de los resultados y la discusión, aportamos una visión analítica y constructivista del estado de la cuestión en el momento histórico.

\section{Resultados y discusión}

\subsection{Del libro de gimnástica al libro de sport (1820-1899)}

Los primeros tratados gimnástico-deportivos que fueron publicados en Catalunya deben circunscribirse principalmente a Barcelona, como capital económica y cultural del Principado. No obstante, las obras impresas en Barcelona fueron divulgadas más allá del territorio catalán.

Después de los frustrados intentos ilustrados de activar prácticas patrióticas y socializadoras a través de los juegos y deportes tradicionales en el marco de la Constitución de Cádiz (Torrebadella, 2013c), el obscurantismo temeroso del absolutismo fernandino no dejó oxígeno para restablecer un asociacionismo cultural, científico o recreativo. Las prácticas tradicionales de la usanza militar y aristocrática, como la esgrima, la equitación o el baile, servían de instrucción para el abolengo de la nobleza. 
Solamente en la breve transición del Trienio Liberal (1820-1823) fue cuando la juventud salió de su estancamiento social, corporal y emocional. En las grandes ciudades como Madrid y Barcelona, y en otras ciudades portuarias e industriales del Norte y del Sur del país floreció una pujante juventud burguesa deseosa de nuevas atracciones y estimulaciones. En los ejercicios y juegos corporales tradicionales, esta juventud encontró un espació de confraternización social. La colonización cultural de la Gran Bretaña puso durante el período Isabelino un distintivo a una sociedad elitista, que concentraba jóvenes varones formados intelectualmente en los colegios extranjeros de Francia, Prusia y, especialmente, de Inglaterra. Fueron los jóvenes que estudiaron en las public schools los que trajeron consigo costumbres y recreaciones del estilo de vida británico. Entre los ejercicios gimnásticos de la época también se consideraban las prácticas como la caza, el paseo, la esgrima, el baile, la natación, el remo o la equitación. Por otro lado, como ejercicios recreativos y saludables, los tratados higiénicos de entonces los recomendaban especialmente a las personas sedentarias y para robustecer a la juventud. Asimismo, la gimnástica moderna se abría paso a partir de un renacimiento de la cultura física que se estaba gestando en los países más avanzados de Europa (Torrebadella, 2014b). La gimnástica y los ejercicios acrobáticos se pusieron de moda entre la juventud, así como otras prácticas recreativas que tenían como epicentro los incipientes gimnasios de la época (Torrebadella-Flix, Olivera-Betrán y M-Bou, 2015).

Esta instruida y próspera juventud también deseaba ensanchar sus dominios y posicionarse románticamente en el mundo. La literatura novelística, científica, técnica, política o filosófica era administrada por una libertad de imprenta que se manifestó con la presencia de nuevas industrias editoriales y una emergente prensa y revistas de todo tipo. Existía, pues, una ansia por recuperar tantos años de atraso cultural y científico. El libro tenía un valor social estimable que distinguía a quién lo poseía.

Doblemente reconocida era la persona -caballero o dama, señorito o señorita- que, además de cultivar el cuerpo con el sano ejercicio físico, también se ilustraba ampliando conocimientos sobre él a través de la lectura de un encarecido libro, que además era la novedad del momento.

En Barcelona, el primer libro propiamente del ámbito gimnástico-deportivo que presentamos fue publicado durante en el Trienio Liberal, Tratado de esgrima a pie y a caballo (1823), de Eudaldo Thomase, distinguido maestro de todas las armas. En este período también se publicó el proyecto del Instituto Gimnástico-Militar de Miguel Roth $(1820,1823)$, que trataba de imitar el modelo gimnástico que el catalán de Valencia, Francisco Amorós, estaba realizado en Francia. Sin embargo, la obra de Thomase, que se presentaba bajo la escuela de la esgrima francesa, y el proyecto de Roth quedaron frenados en la Década Ominosa (1823-1833), que silenciaba toda influencia extranjera. Al fin y al cabo, esta obra ya testimoniaba el influjo que en España iba a protagonizar la esgrima francesa y otras modas parisienses durante el siglo XIX.

El emergente sport de influencia inglesa llegó a España conceptuado en el entonces campo de las prácticas ecuestres. Así, los tratados que atendieron a la creciente afición de las nuevas técnicas civiles de montar, para la enseñanza del nuevo sport, no tardaron en aparecer. Joaquín Blanca publicó Elementos de equitación, o verdaderos principios de la escuela de a caballo, para uso de los caballeros y damas que deseen aprender tan noble como honesto y útil ejercicio (1839) y, más tarde, Pedro Bonnevíe dio a la luz el Nuevo manual de equitación: o arte de montar a caballo para uso de las señoritas, caballeros y militares (1848). Ambos eran profesores de escuelas de equitación de Barcelona, y con estos tratados acercaron al público los nuevos métodos más deportivos e higiénicos de aprender a montar, indicando también el modo de montar de las damas.

Además de la esgrima y la equitación, otro de los ejercicios de carácter lúdico y gimnástico que se revitaliza fue el baile, que a principios del siglo XIX representó el mejor atractivo de recreación física de la alta sociedad y de la burguesía emergente (Capmany, 1947). El conocido profesor Antonio Biosca aportó un pequeño manual para aprender las danzas de moda que provenían de París, Arte del danzar (1832).

Otra práctica señalada fue la tauromaquia. La Barcelona del siglo XIX fue una de las mejores plazas de la lidia española y a mediados del siglo ya existía Sociedad Gimnástica-tauromáquica (Torrebadella, 2012c). El comprobar que algunos jóvenes deseasen demostrar su virilidad en este sport genuinamente español, no debería sorprendernos en una época de excentricidades románticas, de desafío al riesgo y a la fortuna como ya fuera el elevarse en un aventurado aerostato (Torrebadella, 2014a), y así tal lo cuenta la Historia de los aeronautas y de los globos aerostáticos. Acompaña esta historia una descripción detallada de la ascensión que hizo M. Arban en la tarde del día 19 de septiembre de este año, en unión del intrépido catalán D. Eudaldo Munné (1847). De igual modo, Los toros: modo de torear en la plaza a pié y a caballo. Tauromaquia completa puesta al alcance de todos. Escrito conforme a los preceptos de_ _ y otros famosos lidiadores (1850), por el famoso y malogrado torero Francisco Montes, es un testimonio de lo que acabamos de mencionar.

Otras de las modas aburguesadas fueron la caza y la pesca. En 1831 aparecía un ilustrado tratado que se presentaba como la traducción de una obra francesa: Breve tratado de caza y pesca, en donde se demuestran 
varios modos de cazar pájaros pequeños y otras aves, como asimismo el modo de pescar anguilas y otros peces en agua dulce. Al respecto, la nueva caza venía a substituir a una aristocrática afición hasta entonces privilegio dinástico de la nobleza. A partir de la Orden de 2 de febrero de 1837, que anunciaba que "todos los españoles pueden cazar, sin otras trabas ni limitaciones que las que a todos imponen la justicia, la equidad y la conveniencia colectiva o social", la práctica de la caza fue tomando carta de naturaleza como práctica deportiva (Argullol, 1884, p. 33). Las prescripciones de los higienistas siempre se refirieron a la caza como un excelente ejercicio físico. El higienista barcelonés Pedro Felipe Monlau $(1846,1847)$ así lo indicaba en sus reputados tratados de higiene. En la década de los sesenta asistimos a un inició a un incipiente asociacionismo recreativo y cultural representado también por clubs o círculos privados de esgrima, baile, equitación, gimnasios y sociedades cinegéticas (Pujadas, 2010; Torrebadella, 2012c; Torrebadella-Flix, Olivera-Betrán y M-Bou, 2015). De este período es representativo el tratado de La caza. Derechos y deberes del propietario y del cazador (1867), de José de Argullol y Francisco Maspons:

\begin{abstract}
"Solamente, pues, puede considerarse en nuestros días, como ejercicio o una diversión lícita y propia del hombre, que ocupado constantemente en otra fatiga pesada, o en negocios arduos y difíciles, busca en esta diversión del campo, una ocupación higiénica y que distraiga el ánima de la alterada vida de las ciudades. De esta manera comprendemos el verdadero cazador moderno, y de no ser así, no merece este nombre y mucho menos merece la protección que en todas las naciones dispensa la ley a los cazadores y a la caza en especial. El buen cazador respeta y acata todas las disposiciones que tienen por objeto conservarla y aumentarla su número si es posible. El que no lo hace, ya hemos dicho, no merece este nombre; debe llamarse simplemente destructor." (Argullol y Maspons, 1867, p. VI-VII)
\end{abstract}

En 1877 se conocía en Barcelona la Asociación de Aficionados de Caza y Pesca de Cataluña y, un año más tarde, un Boletín que representaba el órgano oficial de la entidad que coadyuvaba a la observancia de las leyes encaminadas a la conservación y fomento de los animales objeto de la caza y de la pesca (Badia, 1879). En Cataluña, la sociedad de Barcelona fue la primera en constituirse, siguiendo luego, a imitación de ésta, la constitución de otras asociaciones de caza en Sabadell, Reus, Mataró, Figueras o Gerona (Asociaciones de aficionados a la caza y pesca de Cataluña y del Principado, 1886). Por tanto, ante esta proliferación de sociedades de caza, en esta época se publicaron algunos libros sobre el asunto. R. Villalta tradujo Manual del cazador (1872) de Renard; Manuel Saurí, La caza de la Perdiz (1877); Andrés Guerra, Secretario y fundador de la Asociación de aficionados de caza publicó Consideraciones sobre la caza de la perdiz con reclamo (1878); y el jurista Joaquín Badia, De la caza y su legislación (1879).

La percepción higiénica y recreativa de la caza fue expresada por José de Argullol en La caza desde el punto de vista histórico, filosófico e higiénico (1884, p. 47), al admitir que cuanto era de conveniente "al hombre de este siglo la regeneración física y el descanso del espíritu que la caza proporciona". Argullol mencionaba que los modernos higienistas como Tourtelle o Levy, recomendaban el ejercicio de la caza para todos aquellos individuos de actividades intelectuales y sedentarias.

Coincidiendo con el funcionamiento de los primeros establecimientos o baños de oleaje en la playa de la Barceloneta se publicaron algunos tratados relacionados con los baños y la natación. Uno de los más populares fue el anónimo Arte de nadar y bañarse con provecho (1861), que citaba los divulgados conocimientos del italiano Oronzio Bernardi (1807). En esta obra ya se aconsejaba la creación de escuelas de natación y el modo más conveniente de construir piscinas para facilitar el aprendizaje. Asimismo, los manuales de higiene de la época ofrecían conocimientos y consejos para practicar los baños de mar y también la natación. En estos años los baños de mar en Barcelona gozaban de un cierto existo, así lo confirma la Guía del bañista o reglas para tomar con provecho los baños de mar (1877, p. 11) del doctor Bataller, que deseaba "vulgarizar la higiene de los baños de mar, poniéndola al alcance de todos".

A partir de mediados del siglo XIX con la incorporación de los primeros establecimientos gimnásticos de carácter higiénico fueron publicados algunos tratados y manuales de gimnástica. En Barcelona las primeras obras de esta índole fueron a cargo de Antonio Moratones, Nociones elementales de gimnasia, para jóvenes de ambos secsos (1863); y de Joaquín Lladó, Nociones de gimnástica higiénica, aplicables a las escuelas de instrucción primaria de uno y otro sexo como elemento de educación física y de utilidad en todas las edades y para todas las clases de sociedad (1868). El tratado de Lladó fue muy valorado, puesto que dispuso de cuatro ediciones, publicándose la última en 1912. En todo caso, ambas obras sucumbieron ante el éxito del Manual popular de gimnasia de sala médica e higiénica del Dr. Schreber (1861) que la editorial de Bailly - Bailliere publicó en Madrid; obra que fue el negocio más importante de la gimnástica española del siglo XIX (Torrebadella, 2014c). 
En 1888 el gimnasiarca barcelonés Joaquín Ramis, en una obrita cuyo título era: Programa de gimnasia en general y de gimnasia higiénica, médica y utilitaria en particular según los adelantos, nuevos principios y reglas, apoyados en el arte y la ciencia de los nuevos tiempos, criticaba que aún no se hubiera publicado ningún libro que tratase el arte de la gimnasia con el rigor científico suficiente: “...la falta de método de que adolece el arte; pues no existe libro alguno que enseñe, o haga ver siquiera lo que significa, y lo que de su ejercicio puede esperarse" (Ramis, 1888, p. 12). Ciertamente la afirmación de Ramís era verdad, puesto que en Barcelona solamente se habían publicado, además de las obras ya citadas, la retórica obra La Gimnástica Cristiana (1876) del doctor Letamendi, algunas obras del joven gimnasiarca David Ferrer, De la utilidad general de la Gimnasia y acción que ejercen sobre el organismo humano sus diferentes ejercicios (1883), Nociones de anatomía útiles para practicar la gimnasia racional (1883); una obrita de Nicolás Camús plagiada (Llaverias, 1935; Torrebadella, 2011b), Nociones de Gimnasia (1885), aunque según Dalmau (1947, p. 46), "el libro se vendió mucho y Camús realizó, con la edición, un excelente negocio”. De este mismo año, según Llaverias (1935), es conocida la obra del Manual práctico de gimnasia de jardín y salón (1885), del editor Salvador Manero. Se trataba de una económica obrita plagiada de un autor francés (Torrebadella, 2011b), que resumía los ejercicios del Manual popular de gimnasia del Dr. Schreber.

De esta época es también la obra de Guillermo Depping, Fuerza y destreza, Agilidad- Ligereza- Flexibilidad: Ejercicios corporales en la antigüedad y en los tiempos modernos (1886); en otras palabras, una evocación histórica de las proezas mecánicas y orgánicas del cuerpo humano.

En estos años, Barcelona era una ciudad de numerosos y concurridos gimnasios, a la sazón el pedestal de la cultura física que posibilitó la emergencia del asociacionismo deportivo de la ciudad (Torrebadella-Flix, OliveraBetrán y M-Bou, 2015). Uno de los gimnasios más emblemáticos era el de Eduardo Tolosa, uno de los pocos catalanes que estudió en la Escuela Central de Gimnástica (Madrid, 1887-1892), que abrió (con título de profesor oficial de Gimnástica) un Gimnasio Médico en la c/ Duc de la Victoria, núm. 3 y 5 (Torrebadella y Arrechea, 2015). Sobre este gimnasia escribió Ramón Garriga (1894) un opúsculo llamado Semblanzas gimnásticas. Esta obrita representa una ingenua caracterización literaria de la personalidad -esbozos biográficos- de los rasgos más destacados de algunos de los personajes que asistían al gimnasio de Eduardo Tolosa.

Los primeros espectáculos deportivos de adscripción popular acaecieron ante la industria y negocio del juego de pelota, en aquella época representado por los frontones Barcelonés y Condal creados en 1893 y 1896 respectivamente. El juego de pelota. El Frontón y galería de pelotaris (1893), es una de la incipientes obras que esbozan el perfil biográfico en torno a la popularidad de la primeras figuras del deporte.

Hacia finales del siglo XIX la bibliógrafa que circulaba en España estaba impresa en Madrid y atendía a cubrir las necesidades docentes de los profesores de gimnástica en los Institutos de segunda enseñanza. Ante la escasa calidad de las obras, en 1894 la Asociación de Profesores Oficiales de Gimnástica acordó abrir un concurso para premiar la obra de mejor calidad, pero una circular de la Dirección de Instrucción Pública suprimió los libros de texto y el concurso quedó desierto (Concurso útil, 1894; Marín, 2009). Dicha prohibición y la preferencia sobre la gimnástica de los juegos corporales se prestaron tratados como el de Juegos infantiles. Recreos útiles para la infancia y la juventud (1896). En esta obra de Julián Bastinos se aportaba un conjunto de recursos lúdicos con un carácter pedagógico entre los que se encontraban los llamados juegos gimnásticos, o que hoy llamaríamos deportivos. Sobre los juegos, pero en otro orden, una obra de gran repercusión fue el Manual del ajedrecista (1897) de Martín Ricart, que testifica la significativa trayectoria de Barcelona en la promoción de este deporte de salón (Brasó, 2013, 2016).

Por otro lado, algunos profesores de gimnástica de los Institutos de segunda enseñanza publicaron los programas de la asignatura (Torrebadella, 2009, 2011b). Entre los primeros se encuentra el Programa de lecciones de gimnasia (1893) de David Ferrer, profesor del Instituto de Segunda Enseñanza de Barcelona, en el cual se identifica la opción de contenidos curriculares 1.

A partir del último cuarto del siglo XIX, el espíritu histórico-romántico y nacional catalán se impregnó de contenidos científicos, culturales y antropológicos. En este contexto intelectual conocido con el nombre de Renaixença (Renacimiento), el excursionismo fue entendido como un poderoso punto de encuentro entre el

\footnotetext{
${ }^{1}$ El programa consta de 84 lecciones. Las 20 primeras lecciones son relativas a conceptos teóricos: Anatomía, Fisiología, mecánica del movimiento, leyes del ejercicio físico, acción y utilidad de los ejercicios gimnásticos e historia. La parte que podríamos llamar más práctica introduce ejercicios a manos libres o fundamentales (lección 21 a la 40), ejercicios en aparatos portátiles: pesos, mazas, barras (lección 41 a la 44), ejercicios sistema Pichery y Gimnasia sueca (lección 45, 46 y 54), ejercicios de lucha, boxeo francés, esgrima de palo, sable y fusil (lección 47 a la 53), ejercicios con aparatos: escaleras, pértigas colgantes, paralelas, cuerdas, muros, caballo, barra fija y percha Amorós (lección 55 a la 69), juegos educativos: billar, bolas, bochas, tejo, rayuela, peonza, boliche, la comba, cuatro esquinas, el marro, los zancos, el aro, volante, de pelota, etc. (lección 71 a la 76), baños y amasamiento (lección 77), ejercicios de natación, regateo, patinaje, equitación, velocípedo, tiro al blanco y colonias escolares (lección 79 a la 84).
} 
hombre y el conocimiento del medio físico. El retorno a la naturaleza del romanticismo se entroncaba al análisis positivista de la ciencia. El descubrimiento del territorio geográfico, geológico, biológico, folklórico, etnográfico o histórico, fueron los primeros objetivos que se marcó el excursionismo catalán de finales del siglo XIX y principios del XX. En este ámbito se ubicó un primer grupo de jóvenes intelectuales de la burguesía barcelonesa. Las primeras expresiones institucionales del excursionismo fueron iniciadas en 1876 con la creación de la Associació Catalana d'Excursions Científiques. Esta entidad fue el punto de partida que inspiró y marcó el modelo de otras asociaciones excursionistas que surgieron a posteriori. No obstante, las primeras manifestaciones del excursionismo aún no fueron ubicadas como prácticas deportivas.

El excursionismo generó una abundante y rica bibliografía, testimonio del alto grado de dinamismo y de compromiso por la recuperación cultural y científica del país (Cataluña). Así, las descripciones geográficas, geológicas o alusiones a descubrimientos arqueológicos, se combinaron con la descripción de los itinerarios de montaña y las narrativas de las ascensiones alpinas. El interés romántico inicial del excursionismo catalán y sus vínculos nacionalistas, hicieron que la mayoría de estas obras fuesen escritas en lengua catalana. Las publicaciones, testimonios de los viajes excursionistas, fueron escritas como relatos de campo revistiendo un carácter literario e inclusive científico. Asimismo, en las narraciones podemos descubrir las primeras guías o itinerarios excursionistas. Entre los principales autores y obras hemos de citar a Artur Osona, Guia general de las montanyas del Monseny (1879), que según Faura (2002), puede ser considerada como la primera obra guía de itinerarios del excursionismo catalán2; Verdaguer, Excursions i viatjes (1887); Bosch de la Trinxeria, Records d'un excursionista (1887); Francesc Maspons, L'excursionisme català (1894); o Lluís Marià, Noves excursions a la Pica d'Estats (1897).

En 1894, Francesc Maspons realizó en el Centro Excursionista de Cataluña un discurso-memoria con el título L'excursionisme català presentaba los resultados obtenidos por el excursionismo catalán desde su creación. En esta memoria se remarcó el bien que el excursionismo había hecho a Cataluña, lo que valía y lo que representaba. Además se citaron aquellos proyectos que aún estaban pendientes y aquellos que podían también realizarse. Francesc Maspons remarcó que el excursionismo catalán fue creado, a diferencia de las sociedades alpinas extranjeras, con un objeto conciso y diferente del que estas se propusieron, es decir, el estudio geográfico de las montañas y el recreo o divertimento. En cambio, el excursionismo catalán fue concebido como un significativo medio cuyo objetivo residía en el conocimiento profundo de Cataluña para su completa regeneración. Por eso Maspons argumentaba que bajo ningún concepto el excursionismo catalán fue fijado por influencia del alpinismo extranjero, puesto que éste nada tenía que ver con buscar el "espíritu del país"3. Si bien primeramente el excursionismo fue conceptuado como una práctica recreativa saludable, cultural y científica, en poco tiempo adquirió aires más deportivos. Hacia finales del siglo XIX, en las asociaciones excursionistas fueron produciéndose escisiones de opiniones que deseaban un mayor acercamiento a las actividades puramente deportivas, al igual que lo hacían los clubes alpinos europeos.

La bicicleta fue la que trajo la verdadera y popular anglomanía por el sport. En 1895 se constituía a iniciativa de las sociedades ciclistas barcelonesas la Unión Velocipédica Española (1901, UVE) y tres años más tarde la Unión Velocipédica Catalana (Torrebadella, 2012c). Varios fueron los manuales publicados en España sobre el ciclismo y uno de los mejores fue el Manual del Velocipedista, del Doctor Eduardo Blasco (ca. 1895). Era un "libro completo y recomendable", puesto que incorporaba los contenidos de "las mejores y más modernas publicaciones extranjeras sobre la materia" (Blasco, 1895, p. 1). Este manual fue una referencia indiscutible para los velocipedistas de la época, acercó y popularizó los consejos técnicos que debían considerarse desde un punto vista higiénico. Esto sucedía en un momento en el que el ciclismo estaba en auge en toda España y el liderazgo de la UVE se mantenía desde Barcelona; de manera que este organismo, ante los continuos desordenes en la organización de los campeonatos y algunas disputas territoriales, quedó en 1899 emplazado en esta ciudad (Canto, 1915).

En estos años algunos clubes de sport y gimnasios de la ciudad estaban ya confraternizando relaciones amistosas con la colonia anglosajona y practicaban un juego llamado foot-ball, que en poco tiempo fue elevado a la categoría de primer deporte de la ciudad (Torrebadella, 2012d). Sin embargo, los sportsmen echaban en falta consejos técnicos para prepararse físicamente a los sports. Baldomero Álvarez (1897, p. 177), director de la revista Barcelona Sport daba a conocer que "muy pronto se publicará en esta -se refiere a Barcelona- un Tratado de entrenamiento y preparación sportivo, en el que colaboran dos escritores muy conocidos y aptos en

\footnotetext{
${ }^{2}$ La primera edición fue editada en 1879. Dispone de varias ediciones corregidas y aumentadas: $3^{a}$ de 1886 y $4^{a}$ de 1899.

${ }^{3}$ F. Maspons citaba las asociaciones excursionistas que fueron creadas en España siguiendo el modelo del Centro Excursionista de Cataluña: La Sociedad de Excursiones Recreativas de Barcelona, la Asociación Excursionista llerdanesa de Lérida, el Centro de Excursiones Científicas-Literarias de Sevilla, "Lo Rat penat" de Valencia, la Sociedad de Excursiones Bilbaínas, "La Expedición" o Sociedad de Excursiones de Palma de Mallorca y la Sociedad Española de Excursiones de Madrid.
} 
la materia. Dicho tratado irá precedido de un prólogo, escrito por una de las notabilidades médicas de Barcelona, consumado ciclista".

\subsection{Del libro de sport a las primeras colecciones $(1900-1910)$}

En el primer decenio del siglo se iniciaron las primeras propagandas para divulgar una cierta literatura técnica del deporte. Barcelona estaba liderando el movimiento gimnástico-deportivo español y muchas iniciativas surgían de las inercias asociativas creadas en los gimnasios de la ciudad y de la entonces mejor revista deportiva del país como era Los Deportes (Torrebadella y Olivera, 2013). Una de estas empresas fue la Federación Gimnástica Española (FGE, 1898), cuyos estatutos se imprimieron en Barcelona. Los incentivos propagandísticos para divulgar la cultura física tenían como protagonista destacado a David Ferrer, vicepresidente de la FGE, el cual presentó la Cartilla gimnástica higiénica de carácter popular para la divulgación y propaganda de esta índole de conocimientos (1900); una obra que fue premiada por el Comité Ejecutivo de la FGE y publicada como monografía por la revista Los Deportes.

Sin embargo, el deporte de una Barcelona en expansión industrial y económica no atiende a las necesidades higiénicas de las clases subalternas. La excesiva concentración de la población, la contaminación de la industria y la falta de salubridad urbana, atacaba especialmente a las familias obreras con menos recursos. La tuberculosis se presentó como la lacra de esta época y a propósito aparecieron algunas publicaciones que se ocuparon del asunto. Una de ellas fue La gimnástica respiratoria en las enfermedades de pecho (1901) del doctor Agustín Bassols, que con una sencilla explicación aportaba los ejercicios gimnásticos respiratorios más adecuados para varias afecciones del pecho. En este orden, otra obra destacada se encuentra en la tesis doctoral de Rafael Rodríguez, Estudio de la gimnástica desde el punto de vista de la Higiene pública (1902). Narciso Masferrer (1902, p. 541) destacaba, entre los tantos méritos de la obra, que principalmente venía a "enriquecer la biblioteca gimnástica, que tan pocos volúmenes buenos atesora".

Una de las publicaciones más destacadas de la FGE (1902) fue el libro de actas de la Asamblea de Zaragoza celebrada en 1901. Las ponencias publicadas fueron las del Dr. Andrés Martínez Vargas, "Popularización de la gimnasia desde el punto de vista higioterápico"; Federico Climent, "profesorado oficial de gimnasia. Plan de organización de dicho cuerpo"; Dr. Pedro Cercós, "La Gimnasia en las profesiones manuales"; Vicente Pinedo, "Instituciones post-escolares"; Carlos César Fernández, "Higiene y condiciones que deben reunir los gimnasios"; Joaquín Cebeira, "Algo sobre educación física de la mujer"; Enrique Robledo, "Breves apuntes acerca de la importancia y aplicaciones de la gimnástica”. Además de las actas de esta Asamblea, algunas conferencias o discursos se publicaron como separatas; una fue la de Enrique Robledo (1902).

En una coyuntura del discurso regeneracionista la mujer fue objeto de frívolas instrumentalizaciones. Los ejercicios gimnásticos en el bello sexo (1903) de Julián de las Barreras, unas de las poquísimas obras monográficas acerca de la gimnástica femenina, presentaba una parte práctica de ejercicios fundamentales para la mejora de la condición física y preservación de la salud. Cuasi la totalidad de estos ejercicios estaban señalados como corrección a las dolencias y variaciones del periodo menstrual.

La primera publicación importante del deporte publicada en España fue el Manual de Sport, del publicista Antonio Viada (1903). Aunque fue publicada en Madrid, la incorporamos como una excepción, ya que el autor, natural de Mataró, estuvo muy ligado al deporte barcelonés4.

Esta obra trata extensamente un sinfín de deportes que, poco a poco, y en cosa de unos cuantos años, fueron introduciéndose en la vida cotidiana de los barceloneses: ciclismo, automóvil, foot-ball, rugby, tennis, basketball, golf, hockey, natación, water-polo, pedestrismo, gimnasia, boxeo, lucha, skating y skating-hockey, etc.

La obra de Antonio Viada ilustra y propaga el deporte siguiendo el modelo inglés; una contribución que aún en España no se había generalizado. En aquella época el deporte era muy minoritario, incluso algunos de los deportes tratados en el Manual, tardaron varias décadas en aclimatarse, como en el caso del basket-ball, football rugby o el skating-hockey. Puede afirmarse que durante la primera década del siglo XX el Manual de sport fue el único referente importante del deporte publicado en España. Además, por la copiosa temática abordada, la obra merece ser considerada como la primera enciclopedia deportiva publicada en España. No obstante, Viada (1906) aún insistía en la necesidad de ilustrar enciclopédicamente a los deportistas a través de revistas y más libros en la materia.

\footnotetext{
${ }^{4}$ Antonio Viada Viladesau (1862-1914), industrial de Mataró que entre finales del siglo XIX e inicios del XX destacó como periodista y aficionado a los deportes, sobre todo al ciclismo y al automovilismo. Viada colaboró en la revista Los Deportes, en El Mundo Deportivo y en la sección de "Sport" de la llustración Española y Americana. Desde Madrid estuvo vinculado junto a Claudio Rialp en la constitución y promoción de la Unión Velocipédica Española.
} 
Como ya indicó Fusté (1997), en agosto de 1905, en Los Deportes se presentaba la "Biblioteca Gimnástica del Gimnasio de Colón", informando a los lectores que podía ser consultada públicamente todos los días de 12 a 15 horas y de 19 a 22 horas (Llaverias, 1905a). Como venía siendo costumbre desde hacía varios años, el Gimnasio de Colón organizó en 1906 el tercer certamen literario, que generalmente se centraba en la temática en torno a la educación física. El premio consistía en la publicación del artículo, pero para poder participar en él, se pedía ser autor de alguna obra o artículo "relativo a la gimnasia o a conocimientos afines", además de poseer el título de profesor oficial de gimnástica, para acceder al premio nacional (Llaverias, 1905b).

En 1906 Los Deportes comentaba que en Barcelona ya se podían localizar algunas obras en torno a la gimnástica. Asimismo lamentaba que la Biblioteca popular de los Manuales Soler, que ya llevaba publicados 65 tomos, todavía no hubiese publicado ningún tratado de gimnástica.

"Cada día son más numerosas en Barcelona las librerías que poseen en venta las obras relacionadas con el estudio de la gimnástica. No hace muchos años que nos hallábamos con libreros que estaban en la creencia de que nada había publicado tocante a este arte." (Los Deportes, 1906, p. 894-895)

Con el cierre del Gimnasio de Colón en 1906, Amadeo Llaverias (1935) depositó su extensa y valiosa biblioteca en la dirección de Los Deportes. Aprovechando la oportunidad, la revista realizó una campaña de difusión de los conocimientos útiles de esta Biblioteca, por lo cual se obsequió con un ejemplar a todos los que acudieron a la imprenta de Los Deportes -calle Valencia, núm. 200- acompañados con un talón que se publicó en la sección de anuncios. Así, desde el día 22 al 27 de octubre se regalaron libros, uno por persona, "a elegir entre varios de los que figuraban en la Biblioteca Circulante del Gimnasio de Colón de Barcelona”5. Con el cierre del Gimnasio de Colón, el 11 de noviembre de 1906, se procedió al almacenamiento de la biblioteca y en 1909 se inició la estampación del Catálogo, que primeramente fue publicado por la Imprenta Filiol en 1910 (Llaverias, 1910). A partir de entonces la Biblioteca fue puesta a la venta, siendo adquirida en 1935 por la Generalitat de Catalunya. Los sucesos de la Guerra Civil llevaron la biblioteca al Comité Olímpico Español y posteriormente pasó a formar parte de la Biblioteca Deportiva Nacional (Berasategui, 1998, 2008; Fusté, 1997; Torrebadella, 2009).

A falta de una obra de pedagogía práctica de la gimnástica en el ámbito escolar, el manual de Educación de los niños (1906) de Federico Climent, miembro de la FGE, puso en la escena popular y familiar de las clases medias la importancia de la educación física y los juegos corporales.

En este decenio, pocos fueron los libros publicados en torno al deporte. Apenas podemos citar una escasa bibliografía sobre excursionismo con obras de August Cesar, Pirineu Català: Guia itinerari de l'excursionista a Camprodón (1902) o Juli Soler, La Vall d’Aran: Guía Monogràfica de la Comarca (1906); obras aisladas que trataban de cubrir las necesidades del momento, como el Tratado teórico-práctico de esgrima de espada (1905) del maestro Eugenio Pini; o el Tratado de Ju-jutsu [sic] y sus secretos, traducido del japonés por C. D. T. (Anónimo, 1907)6.

Destacar también el alpinismo como el primer deporte de montaña de donde también surgirán las primeras prácticas de los llamados deportes de invierno. Los Estatutos del Club Alpino Español. Sección de Cataluña (1909), ya confirman el cambio de orientación que en pocos años va a experimentar el excursionismo catalán hacia su proceso de deportivización.

La importancia que adquieren los establecimientos llamados gimnasios higiénicos, muchos de ellos también concebidos como gimnasios médicos y ortopédicos, tenía en la obra de Max Herz, Manual de iatro-gimnasia (1907), una documentación técnica de primerísima garantía. Esta obra que trata de la gimnasia terapéutica, completaba la escasa literatura sobre la materia. La iatro-gimnasia de Max Herz -"mi sistema de las potencias curativas de la gimnasia"- era una extensión más científica de la gimnasia medicatriz del sueco Pehr Henrik Ling y de la mecano-terapia de Gustavo Zander. Max Herz consideraba que había que someter la gimnasia terapéutica a las bases científicas de la física y la fisiología y, por tanto, dotarla de una legitimación científica (Climent, 2001; Jiménez, 2000).

Por otro lado, en el ámbito de la gimnasia higiénica y al alcance de todos, reapareció una obra de mayor alcance popular editada por Salvador Manero: Manual práctico de gimnasia de jardín y de salón: La higiene por

\footnotetext{
${ }^{5}$ Los Deportes, 20 de octubre de 1906, núm. 426, p. 734. Los Deportes, 13 de octubre de 1906, núm. 426, p. 710.

${ }^{6}$ En la Catálogo de la Biblioteca del Gimnasio de Colón (1935, p. 99) se cita: "Apareció en 1907. Va sin pie de imprenta y esta presentado en una forma semi japonesa. El tiraje es en tinta color bistro o bistre."
} 
medio de ejercicios razonados sin necesidad de ningún aparato (1906). Esta sencilla obrita, firmada por León Ugarde y revisada por un doctor en Medicina de la Facultad de Barcelona, tenía el reconocimiento de ser la $3^{\mathrm{a}}$ edición7.

En España no existía ningún proyecto de biblioteca o colección deportiva. La innovación llegó desde Barcelona con la iniciativa del editor J. Molins que impulsó la "Biblioteca Económica de Sport y Cultura Física". El primer número fue el Breve tratado de Jiu-jitsu (1908), al que tenían que haber seguido otros ejemplares deportivos. Llaverias (1935) citaba que "según el testimonio verbal del editor D. J. Molins la tirada fue de 2.000 ejemplares cada edición. Impresos en 1908"8.

\begin{abstract}
"Interesante es el folleto que con el título de breve tratado de Jiu-jitsu se ha puesto a la venta, folleto como volumen, pero cual contenido no deja de ser recomendable, pues que a más de una tan breve como clara explicación del origen de la lucha japonesa, demuestra por medio de grabados las más esenciales presas y llaves conocidas en esta lucha. Este es el primero de los folletos que formará parte de la Biblioteca Económica de Sport y Cultura Física, estando ya en preparación otros folletos, tales como Medios de defensa sin armas, Manual de Gimnasia, Juego de vara y bastón, Esgrima de florete y sable, etc., etc., de los que nos ocuparemos oportunamente.

Esta tan decaído en nuestro país cuanto a sport y cultura se relaciona, que no podemos por menos aplaudir la idea del sr. Molins, vulgarizando en esa Biblioteca Económica los conocimientos que en los demás países forman ya parte integrante de los programas de centros docentes y corporaciones oficiales.

Celebramos que un éxito espontáneo y franco corone los éxitos del editor." 9
\end{abstract}

En estos años el Jiu-Jitsu estaba haciendo furor en Barcelona entre los jóvenes de algunas salas de armas y sociedades deportivas. En poco tempo se publicaron varias obras que todavía acrecentaron la popularidad de esta nueva práctica de lucha japonesa (Gutiérrez, 2007).

En estos mismos años apareció una colección con el nombre "Los sports de moda", de la Editorial IberoAmericana de Barcelona, que incorporó dos títulos que agrupaban varias prácticas deportivas: GimnásticaLawn-tennis (Cavalliotti, ca. 1910) y Foot-ball-Waterpolo-Jiu-Jitsu (Tunmer, Fraysse y Montespin, ca. 1910$) 10$. Ambas obras ilustran una de las primeras tentativas por incorporar las modernas prácticas físicas y deportivas que emergían en el continente europeo11.

A finales de la primera década del siglo pasado es cuando la juventud de los principales colegios de Barcelona ya se había consumado ante el fervor deportivo, sobre todo de ese nuevo deporte todavía llamado foot-ball (Torrebadella y Nomdedeu, 2015). Así surgieron pues, lógicas declaraciones prerrogativas para orientar civilizadamente y desde la doctrina católica, las pasiones y las inercias del deporte juvenil. Dos obritas pusieron el discurso en esta cuestión: una fue del apologético reverendo sabadellense Félix Sardá (1908), representante del integrismo católico, y la otra del Duque de la Salle (1909), máxima autoridad de los Hermanos de las Escuelas Cristianas de Juan Bautista de La Salle.

En 1910, sin apenas desarrollo de la aviación, sorprendió el Curso de aviación de Gaspar Brunet, la primera obra de su clase publicada en España y escrita por un ingeniero industrial barcelonés que se destacó en el terreno de la aeronáutica. Así pues, el Curso de aviación fue la obra que inició una prolífica bibliografía sobre esta materia; un deporte que fascinó a los sportsmen más elitistas de principios del siglo pasado (Canudas, 1983).

\footnotetext{
7 "El conocido editor de esta ciudad don Salvador Manero, ha lanzado hace pocos días a la venta, su, podriamos decir, tercera edición de la obrita: Manual práctico de gimnasia de jardín y salón. En esta nueva edición, que no lleva fecha, se han introducido algunas mejoras y se nos da, en la portada y por vez primera, el nombre del autor: don Léon Ugarde" "Gimnasia", Los Deportes, 1 de diciembre de 1906, núm. 432, p. 894-895).

${ }^{8}$ Parece ser que de esta obra se imprimieron dos ediciones.

9 "Folletos de sport", El Mundo Deportivo, 24 de septiembre de 1908, p. 3.

${ }^{10}$ Ambos libros citados en el Museo Pedagógico Nacional: Bibliografía y Material de Enseñanza (1915).

${ }^{11}$ La $1^{a}$ edición francesa corresponde a Tunmer, N. G. Et Fraysse, Eugéne: Football (Associatión), Armand Colin et Cie., París, 1897 (XV-129 p.; $17 \mathrm{~cm}$.)
} 


\subsection{Repertorio bibliógrafo gimnástico-deportivo (Barcelona, 1820-1910).}

$1820-1829$

[Gimnástica] Roth, Juan Miguel (1820). Proyecto gimnástico militar para la formación de un batallón local de jóvenes españoles de diez a dieciséis años de edad: Que presenta al excelentísimo Ayuntamiento Constitucional de la Ciudad de Barcelona, para su aprobación. Barcelona: Imp. Ifern.

[Gimnástica] Roth, Juan Miguel (1823). Ordenanzas para el régimen y gobierno del primer Instituto Gimnástico-Militar, que deberán observar sus alumnos, individuos del batallón de jóvenes. Barcelona: Imp. Ayuntamiento Constitucional.

[Esgrima] Thomase, Eudaldo (1823). Tratado de esgrima a pie y a caballo: en que se enseña por principios el manejo del florete, o el juego de la espada que se usa en día. Barcelona: Imp. de Narciso Dorca.

$1830-1839$

[Caza y pesca] D. L. A. X. Y. F. (trad.) (1831). Breve tratado de caza y pesca, en donde se demuestran varios modos de cazar pájaros pequeños y otras aves, como asimismo el modo de pescar anguilas y otros peces en agua dulce, acompañado de 17 láminas. Barcelona: Imp. de Ignacio Estevill.

[Danza] Biosca, Antonio (1832). Arte del danzar ó reglas é instrucciones para...las contradanzas francesas ó Rigodones. Barcelona: Imp. Sauri.

[Equitación] Blanca de Ruiz, Joaquín (1839). Elementos de equitación, o verdaderos principios de la escuela de a caballo, para uso de los caballeros y damas que deseen aprender tan noble como honesto y útil ejercicio. Escritos y recopilados de los mejores autores tanto antiguos como modernos. Barcelona: Imp. de J. Oliveres y Monmany.

1840-1849

[Aeróstación] S. A. S. M. (1847). Historia de los aeronautas y de los globos aerostáticos. Acompaña esta historia una descripción detallada de la ascensión que hizo M. Arban en la tarde del día 19 de septiembre de este año, en unión del intrépido catalán D. Eudaldo Munné. Barcelona: Imp. y Lib. de la Sra. Vda. e Hijos de Mayol.

[Equitación] Bonnevíe, Pedro (1848). Nuevo manual de equitación: o arte de montar a caballo para uso de las señoritas, caballeros y militares. Barcelona: Imp. de Manuel Saurí.

$1850-1859$

[Tauromaquia] Montes, Francisco (1850). Los toros: modo de torear en la plaza a pié y a caballo. Tauromaquia completa puesta al alcance de todos. Barcelona: Miguel Blanxart. 
1860-1869

[Equitación] Círculo Ecuestre (1860). Reglamento general del Círculo Ecuestre, reorganizado en 1 de enero de 1860. Barcelona: Imp. de Cristóbal Miró.

[Natación] D. A. M. y B. (1861). Arte de nadar y bañarse con provecho. Barcelona: Est. Tip. de Narciso Ramírez.

[Gimnástica] Moratones Freixa, Antonio (1863). Nociones elementales de gimnasia, para jóvenes de ambos secsos. Barcelona: Imp. de Joaquín Bosch.

[Gimnástica] Ramis Taix, Joaquín (1865). Una verdad o consideraciones sobre la utilidad de la gimnástica. Barcelona: Imp. de Gómez e Inglada.

[Caza] Argullol Serra, José de y Maspons Labrós, Francisco (1867). La caza. Derechos y deberes del propietario y del cazador. Barcelona: Imp. de El Porvenir de la V. Bassas, a cargo de J. Medina.

[Gimnástica] Lladó, Joaquín (1868). Nociones de gimnástica higiénica, aplicables a las escuelas de instrucción primaria de uno y otro sexo como elemento de educación física y de utilidad en todas las edades y para todas las clases de sociedad. Barcelona: Lib. de Juan Bastinos e hijos.

1870-1879

[Caza] Renard, L. (1872). Manual del cazador o arte completo de toda clase de caza Traducción de R. Villalta, aficionado en 30 años de ejercicios de caza mayor y menor. Barcelona: Manuel Saurí Editor.

[Gimnástica] Letamendi, José de (1876). La gimnástica cristiana. Trasunto de un parecer verbal dado por el autor al Excmo. o Ilmo. Sr. Fray Joaquín Lluch y Garriga, Obispo de Barcelona, y escrito y dado a luz por disposición expresa de su Excelencia Ilustrísima. Barcelona: Imp. de Jaime Jepús Roviralta.

[Natación] Bataller Contasti, A. (1877). Guía del bañista o reglas para tomar con provecho los baños de mar. Barcelona: Imp. Renaixença.

[Caza] Saurí, Manuel (1877). La caza de la Perdiz con escopeta, al vuelo y con perro de muestra. Barcelona: Editor Manuel Saurí.

[Caza] Guerra, Andrés (1878). Consideraciones sobre la caza de la perdiz con reclamo. Barcelona: Manuel Saurí.

[Caza] Badia, Joaquín (1879). De la caza y su legislación. Tratado de la caza, pesca y uso de las armas con las leyes vigentes. Barcelona: Est. Tip. de José Miret.

[Excursionismo] Osona i Formentí, Artur (1879). Guia general de las montanyas del Monseny: Amb la versió castellana i francesa, acompanyada del plan de la encontrada. Barcelona: Imprenta de la Renaixensa.

[Pesca] Valverde (1879). Manual del Pescador. Tratado completo de pesca con anzuelo y redes. Acompañado de indicaciones para la conservación y fomento de la pesca, sobre el acuario, etc., etc. Barcelona: Manuel Saurí Editores. 
$1880-1889$

[Gimnástica] Ferrer, David (1883). De la utilidad general de la Gimnasia y acción que ejercen sobre el organismo humano sus diferentes ejercicios. Memoria premiada por el Ateneo Igualadino de la clase obrera en el Certamen científico literario de 1881. Barcelona: Est. Tip. de José Miret.

[Gimnástica] Ferrer, David (1883). Nociones de anatomía útiles para practicar la gimnasia racional. Barcelona: Est. Tip. de José Miret.

[Caza] Argullol, José de (1884). La caza desde el punto de vista histórico, filosófico e higiénico. Memoria premiada en el certamen literario de Manresa el día 3 de diciembre de 1882. Barcelona: Imp. Barcelonesa.

[Gimnástica] Anónimo (ca. 1885). Manual práctico de gimnasia de jardín y salón. La higiene por medio de los ejercicios razonados sin necesidad de aparato. Barcelona: Salvador Manero.

[Gimnástica] Camús, Nicolás (1885). Nociones de Gimnasia. Barcelona: Est. Tip. de Bernabé Baseda.

[Aerostación] Marion, Fulgencio (1885). Globos y viajes aéreos. Barcelona: Editor Daniel Cortezo y Cª.

[Caza] Asociaciones de aficionados a la caza y pesca de Cataluña y del Principado (1886). Asociaciones de aficionados a la caza y pesca de Cataluña y del Principado. Breves consideraciones respecto a la existencia de la primera de dichas sociedades y al establecimiento de la segunda. San Martín de Provençals: Imp. de J. Torrens.

[Gimnástica] Depping, Guillermo (1886). Fuerza y destreza, Agilidad-Ligereza- Flexibilidad: Ejercicios corporales en la antigüedad y en los tiempos modernos. Barcelona: Biblioteca de Maravillas, Daniel Cortezo.

[Excursionismo] Bosch de la Trinxeria, C. (1887). Records d'un excursionista. Barcelona: Imp. La Renaixença.

[Excursionismo] Verdaguer, Jacinto (1887). Excursions i viatjes. Barcelona: La II·lustració Catalana.

[Gimnástica] Ramis Taix, Joaquín (1888). Programa de gimnasia en general y de gimnasia higiénica, médica y utilitaria en particular según los adelantos, nuevos principios y reglas, apoyados en el arte y la ciencia de los nuevos tiempos. Barcelona. Est. Tip. Ed. "La Academia".

$1890-1899$

[Gimnástica] Ferrer Mitayna, David (1893). (Instituto de Segunda Enseñanza de Barcelona) Programa de lecciones de gimnasia. Barcelona: Imp. J. Farriols y Amat.

[Deportes: pelota] J. T. N. G. (1893). El juego de pelota. El Frontón y galería de pelotaris. tomo I. Barcelona: Imp. A. López Robert.

[Gimnástica] Garriga, Ramón Manuel (1894). Semblanzas gimnásticas. Barcelona: Tip. de la Casa Provincial de la Caridad.

[Excursionismo] Maspons y Labrós, Francisco de S. (1894). (Centre Excursionista de Catalunya) L'excursionisme català (Discurs llegit lo dia 1er de febrer per lo president del Centre D. Francisco de S. Maspons y Labrós en la solemne sessió inaugural de 1894). Barcelona: Tip. La Academia de Serra Germans y Rusell. 
[Deportes: ciclismo] Blasco, Eduardo (ca. 1895). Manual del Velocipedista: Arte de montar a bicicleta, biciclo, triciclo, tándem, sociable, etc. Accidentes, modos de evitarlos y sus remedios. Higiene del velocipedista. Obra escrita en presencia de las mejores y más modernas publicaciones extranjeras sobre la materia. Barcelona: Ed. Salvador Manero Bayarri.

[Deportes infantiles] Bastinos, Julián (1896). Juegos infantiles. Recreos útiles para la infancia y la juventud. Barcelona: Lib. de Antonio J. Bastinos, Editor.

[Excursionismo] Marià Vidal, Lluís (1897). (Centre Excursionista de Catalunya) Noves excursions a la Pica d'Estats. Barcelona: Tip. “L’Avenç” de Massó, Casas \& Elias.

[Deportes: ajedrez] Ricart, Martín (1897). Manual del ajedrecista: obra utilísimo no solo a los principiantes si no que también los buenos jugadores por el sin número de casos prácticos que contiene con abundancia de detalles rigurosamente históricos,... Barcelona: Saurí y Sabater Editores.

[Gimnástica] Federación Gimnástica Española (1898). Estatutos de la Federación Gimnástica Española. Barcelona: Imp. y Lit. de José Cunill y Sala.

1900-1909

[Gimnástica] Ferrer Mitayna, David (1900). Cartilla gimnástica higiénica de carácter popular para la divulgación y propaganda de esta índole de conocimientos. Premiada en el concurso abierto por el Comité Ejecutivo de la Federación Gimnástica Española. Lema: Figurémonos que somos una máquina animada (Leyes, Platón). Barcelona: L’Avenç.

[Gimnástica] Bassols Prim, Agustín (1901). La gimnástica respiratoria en las enfermedades de pecho. Barcelona: Tip. Casa Provincial de la Caridad.

[Deportes: ciclismo] Unión Velocipédica Española (1901). Estatutos de la Unión Velocipédica Española, aprobados en el $5^{\circ}$ Congreso. Barcelona: Ed. Pons y Sorarrain.

[Gimnástica] Federación Gimnástica Española (1902). Asamblea de Zaragoza. Barcelona: Imp. J. Cunill.

[Gimnástica] Federación Gimnástica Española (1902). Ferias y Fiestas populares de Ntra. Sra. de las Mercedes. Programa y Reglamentos de los concursos que la Federación Gimnástica Española ha de realizar en el Campo de Juego del Parque. Barcelona: Imp. José Cunill.

[Gimnástica] Robledo, Enrique (1902). Breves apuntes acerca de la importancia y aplicaciones de la Gimnástica: discurso leído por su autor en la Asamblea de Zaragoza celebrada en 1901 por la Federación Gimnástica Española. Barcelona: Imp. de José Cunill y Sala.

[Gimnástica] Rodríguez Ruiz, Rafael (1902). Estudio de la gimnástica desde el punto de vista de la Higiene pública. Barcelona: Tip. "La Académica” de Serra Hnos y Rusell.

[Excursionismo] Torras i Ferreri, Cesar August (1902). Pirineu Català: Guia itinerari de l'excursionista a Camprodón. Barcelona: Tip. L’Avenç.

[Gimnástica] Barreras, Julián de las (1903). Los ejercicios gimnásticos en el bello sexo. Barcelona: Los Deportes.

[Deportes] Sportsmen's Club (1903). Estatutos del sportsmen’s club Barcelona: Tip. L’Avenç.

[Deportes: esgrima] Pini, Eugenio (1905). Tratado teórico-práctico de esgrima de espada. Barcelona: Casa Editorial Maucci.

[Gimnástica: educación] Climent Terrer, Federico (ca. 1906). (Manuales Soler núm. LXIII). Educación de 
los niños. Barcelona: Sucesores de Manuel Soler.

[Excursionismo] Soler i Santaló, Juli (1906). La Vall d’Aran: Guía Monogràfica de la Comarca. Barcelona: L'Avenç.

[Gimnástica] Ugarde, León (1906). Manual práctico de gimnasia de jardín y de salón: La higiene por medio de ejercicios razonados sin necesidad de ningún aparato. Método práctico en vista de los mejores autores que tratan de esta materia ( $3^{\mathrm{a}}$ ed.). Barcelona: Ed. Salvador Manero Bayarri.

[Deportes: jiu-jitsu] Anónimo (ca. 1907). Tratado de Ju-jutsu [sic] y sus secretos. Traducción del japonés por C. D. T. Barcelona: Imp. "Ibérica”.

[Gimnástica médica] Herz, Max (1907). Manual de iatro-gimnasia: (Gimnasia medicatriz) en forma de conferencias. Barcelona: Herederos de Juan Gili.

[Deportes: jiu-jitsu] Anónimo (ca. 1908). Breve tratado de Jiu-jitsu: principales llaves de defensa que usan los más renombrados campeones de lucha japonesa. Barcelona: Imp. Vda. J. Cunill

[Deportes: educación] Sardá Salvany, Félix (1908). L'sport católich: Conferencia en el Ateneu de Sant Lluis Gonçaga, de la barriada de Sant Andréu de Palomar (Barcelona), ab ocasió de les Bodes d'or de dita fervosa Associació, celebrades lo día 28 de juny del present any, llegida. Barcelona: Lib. Tip. Católica.

[Deportes: alpinismo] Club Alpino Español (1909). Estatutos del Club Alpino Español. Sección de Cataluña. Barcelona: Imp. de M. Berdós Molas.

[Deportes: educación] Salle De Rochemaure, Sr. Duch de la (1909). (Reyalme d'Espanya. Ciutat de Barcelona a Catalunya. Col-legi de la Mare de Deu de la Bonanova) Gran Festa Sportiva. Discurs presidencial "Los sports i llur influència en el caràcter". Aurillac: Imp. Moderrne.

1910

[Deportes: aviación] Brunet Viadera, Gaspar (1910). Curso de aviación: historia retrospectiva de la navegación aérea por lo más pesado que el aire. Técnica de aviación. Construcción de aeroplanos. Barcelona: Imp. Feliu i Susana.

[Gimnástica y deportes] Cavalliotti (ca. 1910). (Los sports de moda) Gimnástica. Lawn-tennis. Barcelona: Ed. Ibero-Americana.

[Gimnástica y deportes] Llaverias Rovirosa, Amadeo (1910). Catálogo de la Biblioteca del Gimnasio de Colón. Barcelona: Imp. Fiol.

[Deportes: fútbol,...] Tunmer, M. M., Fraysse, Eugene, M. M., y Montespin, Rene barón de (ca. 1910). (Los sports de moda) Foot-ball. Waterpolo. Jiu-Jitsu. Barcelona: Editorial Ibero-americana ${ }^{12}$.

\section{A modo de conclusión}

Sin duda alguna la producción literaria de una sociedad refleja su modo de ser de la misma, o al menos de unos estilos de vida que van acomodándose. Cuando un libro se publica quiere decir que hay alguien que lo va a leer, que existe una necesidad o expectativa creada en su entorno. En el siglo XIX el elevado coste de un libro era privativo de las clases cultivadas. Un libro valía el trabajo semanal de un jornalero. Cuando el editor o el autor publicaban la obra debían garantizar de antemano el proyecto, por ello muchos libros de la época se

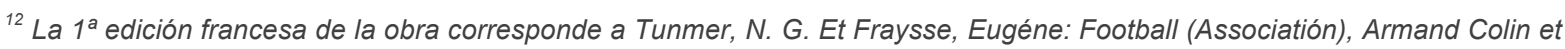
Cie., París, 1897 (XV-129 p.; 17 cm.).
} 
publicaron por fascículos y subscripciones. La tradición librera española tenía una larga experiencia en publicaciones de temática deportiva en torno a la esgrima, la equitación y la caza, destinadas a la nobleza como complemento de su formación militar. La empresa de publicar libros de un género Nuevo para uso higiénico o recreativo era una aventura nueva que conllevaba muchos riesgos. Sin embargo, en Barcelona existía el suficiente número de personas que podían acceder a este tipo de obras. La pujante burguesía barcelonesa y el crecimiento industrial de la ciudad posibilitaban muchas oportunidades de negocio. En Barcelona, pues, paralelo a su crecimiento industrial y burgués, la venta de todo tipo de literatura tenía sus potenciales clientes. Como cita Alfaro (1999), es a través de la lectura que la burguesía se abastecía de dinámicas diferenciadoras de clase, con lo cual y gradualmente iban tomando acceso a los diferentes campos de poder. Uno de estos campos también era el del ocio y el de las prácticas físicas saludables. Esta es la razón principal del porqué se publicaron en Barcelona los primeros libros de deportes, sencillamente porque había suficiente número de aficionados al deporte que los podían comprar. Había entonces una élite intelectual que deseaba ilustrarse como así lo hacía la sociedad victoriana y parisiense de la época. Londres y París eran la referencias culturales de entonces (Torrebadella-Flix, Olivera-Betrán y M-Bou, 2015). La progresiva alfabetización de las clases populares y las aspiraciones de ascenso de las clases medias posibilitaron un nuevo contexto cultural de lectura, que fue favorecido por los cambios técnicos en la impresión de libros, más sencillos, económicos y utilitarios.

El libro es el fermento cultural de una sociedad y, por lo tanto, es portador de un significado contextual histórico y sociológico, que también necesitan conocer los profesionales de la bibliotecología y la documentación, a saber, también el que le atañe los orígenes de la cultura física y el deporte.

\section{Referencias}

Alfaro, H. G. (1999). Teoría e historia de la constitución del campo bibliotecológico español. Investigación Bibliotecológica, $13(26), 6-26$

Álvarez, B. (1897, 17 de abril). De todo un poco. Barcelona Sport, pp. 176-178.

Aquesolo, J. (2000). Apuntes para una historia de la documentación deportiva. Revista General de Información y Documentación, 10(1), 31-67.

Berasategui, M. L. (1998). Amadeu Llaverias, gimnasta i bibliòfil. Apunts, Educación Física y Deporte, 53, 98-102.

Berasategui, M. L. (2008). Fonts bibliogràfiques per a l'estudi de l'educació física i l'esport a Catalunya (1856-1975). Temps d'Educació, 35, 169-196.

Blanco, R. (1925). Don Marcelino Menéndez y Pelayo. Apuntes Bibliográficos. Madrid: Tipografía de la "Revista de Archivos, Bibliotecas y Museos".

Blanco, R. (1927). Bibliografía general de la educación física. Madrid: Hernando.

Blasco, E. (1895, 25 de octubre). Eduardo Blasco. Manual del velocipedista. La Vanguardia, p. 1.

Brasó, J. (2016). Los libros de ajedrez en España (1900-1939): repertorio bio-bibliográfico y estudio bibliométrico. Anales de Documentación, 19(1). Disponible en: http://dx.doi.org/10.6018/analesdoc.19.1.247821

Brasó, J. (2013). Bibliografía de ajedrez existente en España. EFDeportes.com. Revista Digital, 184. Tomado el 11 de julio de 2016 de http://www.efdeportes.com/efd184/bibliografia-de-ajedrez-en-espana-1800-1939.htm

Canto, F. A. (1915). Ciclismo. Barcelona: Lib. Sintes.

Canudas, J. (1983). Història de l'aviació catalana (1908-1936). Barcelona: Edicions de La Magrana.

Capmany, A. (1947). Un siglo de baile en Barcelona. Qué y donde bailaban los barceloneses el siglo XIX. Barcelona: Ediciones Librería Milla.

Climent, J. M. (2001). Historia de la rehabilitación médica. De la física terapéutica a la reeducación de inválidos. Barcelona: Edika Med.

Concurso útil (1894, 16 de febrero). Crónica del Sport, p. 55.

Dalmau, A. R. (1947). El circo en la vida barcelonesa. Crónica anecdótica de cien años circenses. Barcelona: Ediciones Librería Milla. 
Díez Ménguez, I. C. (2000). Las bio-bibliografías: estado actual y metodología. Cuadernos de documentación multimedia, 10, 67-77.

Faura, E. (2002). Antologia literaria excursionista catalana. Tremp: Garsineu Edicions.

Fusté, J. (1997). Breu notícia del Gimnàs de Colón de Barcelona. En La formació inicial i permanent dels mestres, en Actes de les XIII Jornades d'Història de l'Educació als Països Catalans (pp. 243-254). Vic: Editorial Eumo.

Gallego, J. (2005). Estado actual de los estudios bibliográficos sobre el arte en España. Scire, 11(1), 65-82.

Gutiérrez García, C. (2007). Estudio de las primeras obras de artes marciales escritas en español, Revista de Artes Marciales Asiáticas, 2(1), 8-27.

Jiménez, J. (2000). Material gimnástico y terapéutica física (Mecanoterapia). En J. L. Hernández (dir.), Nacimiento e implantación de la educación física en España: Los tiempos modernos (pp. 153-239). Madrid: Ministerio de Educación, Cultura y Deporte. Consejo Superior de Deportes.

Llaverias, A. (1935). Gimnasio de Colón: Catálogo de la Biblioteca del Gimnástico - deportiva y de conocimientos afines. Barcelona: Anticuaria de Antonio Palau Dulcet.

Llaverias, A. (1905a, 26 de agosto). Biblioteca Gimnástica del Gimnasio de Colón. Los Deportes, pp. 549-555.

Llaverias, A. (1905b, 9 de septiembre). Gimnasio de Colón. Los Deportes, p. 282.

Los Deportes (1906, 1 de diciembre). Gimnasia. Los Deportes, pp. 894-895.

Marín, E. (2009). D. Marcelo Sanz Romo, iniciador y propagandista de la educación física en España: Vida y obra (Tesis doctoral). Departamento de Didáctica: Universidad de Alcalá. http://dspace.uah.es/dspace/handle/10017/6344

Martins, M. (2002). El trabajo de los indizadores: factores que afectan al análisis de contenido, Scire, 8, 119-130.

Masferrer, N. (1902, 7 de setiembre). Estudio de la gimnástica", Los Deportes, p. 541.

Menéndez, M. (1876). De Re Bibliographica. Revista Europea, 8(125), 65-73.

Monlau, P. F. (1846). Elementos de higiene privada: o arte de conservar la salud del individuo. Barcelona: Imp. de Pablo Riera.

Monlau, P. F. (1847). Elementos de higiene pública, tomo II. Barcelona: Imp. de Pablo Riera

Museo Pedagógico Nacional (1915). Bibliografía y material de enseñanza. Educación física e higiene escolar. Madrid: R. Rojas.

Pastor, J. L. (1995). La educación física en España: fuentes y bibliografía básicas. Alcalá de Henares: Universidad de Alcalá

Pastor, J. L. (2003). El fondo bibliográfico documental relacionado con la actividad física y deportiva en España. Apunts. Educación Física y Deportes, 94, 14-22.

Pinto, M. (1989). El análisis de contenido: La Indización de documentos. En J. López Yepes (comp.), Fundamentos de información y Documentación (pp. 347-374). Madrid: Eduma.

Pinto, M. (2002). Análisis documental de contenido. En J. López Yepes (coord.). Manual de Ciencias de la Documentación (pp. 419-447). Madrid: Pirámide.

Pujadas, X. (2010). De las élites a las masas: Deporte y trasformación de las formas de ocio moderno en Cataluña (18901936). En X. Pujadas (coord.), La metamorfosis del deporte. Investigaciones sociales y culturales del fenómeno deportivo contemporáneo (pp. 19-39). Barcelona: Editorial UOC.

Schreber, D. G. M. (1861). Manual popular de gimnasia de sala médica e higiénica: o Representación y descripción de los movimientos gimnásticos, no exigiendo ningún aparato para su ejecución, pueden practicarse en todas partes y por toda clase de personas de uno y otro sexo. Seguido de sus aplicaciones a diversas enfermedades. Madrid: Carlos Bailly - Bailliere.

Torrebadella-Flix, X., y Olivera-Betrán, J. (2012). Las cien obras clave del repertorio bibliográfico español de la educación física y el deporte en su proceso de legitimación e institucionalización (1807-1938). Revista General de Información y Documentación, 22, 119-168. http://dx.doi.org/10.5209/rev_RGID.2012.v22.39669

Torrebadella-Flix, X., \& Olivera-Betrán, J. (2013). The Birth of the Sports Press in Spain within the Regenerationist Context of the Late Nineteenth Century. The International Journal of the History of Sport, 30(18), 2164-2196.

http://dx.doi.org.10.1080/09523367.2013.854775 
Torrebadella-Flix, X., Olivera-Betrán, J., \& M-Bou, M. (2015). Origin and Institutionalisation of Sports and Gymnastics Associations in Nineteenth-Century Spain (1822-1900). Apunts. Educación Física y Deportes, 119, 7-54. DOI: http://dx.doi.org/10.5672/apunts.2014-0983.cat.(2015/1).119.01

Torrebadella-Flix, X., y Nomdedeu-Rull, A. (2014). Bibliographic Repertoire of Football in Spain (1900-1936). 121 works to interpret the social impact of football in contemporary history. Apunts. Educación Física y Deportes, 115, 7-32. DOI: http://dx.doi.org/10.5672/apunts.2014-0983.cat.(2014/1).115.01

Torrebadella-Flix, X., y Nomdedeu-Rull, A. (2015). Los primeros libros de fútbol publicados en España (1900-1919). Revista General de Información y Documentación, 25(1) 113-139. http://dx.doi.org/10.5209/rev_RGID.2015.v25.n1.48985

Torrebadella, X. (2009). Contribución a la historia de la educación física en España. Estudio bio-bibliográfico desde 1809 a 1939. Universidad de Lérida [tesis doctoral inédita]

Torrebadella, X. (2011a). La educación física y la actividad gimnástico-deportiva de las mujeres a partir de la bibliografía especializada del siglo XIX. Arenal, 18(1), 147-179.

Torrebadella, X. (2011b). Repertorio bibliográfico inédito de la educación física y el deporte en España (1800-1939). Madrid: Fundación Universitaria Española, Madrid.

Torrebadella, X. (2011c). Vicente Naharro y los juegos corporales en la educación física española de la primera mitad del siglo XIX. Ágora para la Educación física, 13(2), 165-182.

Torrebadella, X. (2012a). Las primeras revistas profesionales y científicas de la educación física española (1882-1936). Apunts. Educación Física y Deportes, 190, 11-25.

Torrebadella, X. (2012b). Las primeras tesis doctorales de la educación física en el espacio científico y profesional sobre la medicina española. Pecia Complutense, 16, 58-88.

Torrebadella, X. (2012c). Los orígenes de una ciudad olímpica: Barcelona y el asociacionismo deportivo decimonónico ante la gestación de los primeros Juegos Olímpicos. Citius, Altius, Fortius, 5(2), 91-134.

Torrebadella, X. (2012d). Orígenes del fútbol en Barcelona (1892-1903). RICYDE. Revista Internacional de Ciencias del Deporte, 27, 80-102. Doi. http://dx.doi.org/10.5232/ricyde2012.02706

Torrebadella, X. (2013a). Crítica a la bibliografía gimnástica de la educación física en España (1800-1939). Anales de Documentación, 16(1) http://dx.doi.org/10.6018/analesdoc.16.1.158851.

Torrebadella, X. (2013b). L'Acadèmia d'Educació Física de Catalunya. Un intent per legitimar un espai institucional i doctrinal de l'educació física en la II República. Apunts d'Educació Física i Esport, 114, 23-35. Doi http://dx.doi.org/10.5672/apunts.2014-0983.cat.(2013/4).114.02

Torrebadella, X. (2013c). La educación física y preámbulos deportivos en el contexto ilustrado y liberal de la primera Constitución española (1800-1814). Rubrica Contemporanea, 2(4), 73-99.

Torrebadella, X. (2014a). Aventura, espectáculo y deporte en los inicios de la aerostación en España (1784-1905). Recorde: Revista de História do Esporte, 7(1), 1-35. http://www.revistas.ufrj.br/index.php/Recorde/article/view/1236/1168

Torrebadella, X. (2014b). La educación física comparada en España (1806-1936). Historia Social y de la Educación, 3(1), 2553. DOI: http://dx.doi.org/10.4471/hse.2014.02

Torrebadella, X. (2014c). La influencia de la profesión médica en la educación física española del siglo XIX: Análisis social del Manual popular de gimnasia de sala, médica e higiénica del Dr. Schreber. Cultura, Ciencia y Deporte, 9(26), 163-176. http://dx.doi.org/10.12800/ccd.v9i26.434

Torrebadella, X. (2014d). Regeneracionismo e impacto de la crisis de 1898 en la educación física y el deporte español. Arbor, 190 (769): a173. Doi: http://dx.doi.org/10.3989/arbor.2014.769n5012

Torrebadella, X. (2014e). Rufino Blanco Sánchez y las fuentes bibliográficas de la educación física y el deporte en España. RICYDE. Revista Internacional de Ciencias del Deporte, 37, 281-284. Doi: http://dx.doi.org/10.5232/ricyde2014.037

Torrebadella, X. (2015). Forjando los Juegos Olímpicos de Barcelona: La contribución de Narciso Masferrer y Sala en la configuración del deporte nacional e internacional (1900-1910). Citius, Altius, Fortius, 8(1), 61-103.

Torrebadella, X., y Arrechea, F. (2015). Los orígenes de una ciudad olímpica. La vida gimnástico deportiva en la Barcelona decimonónica. Madrid: CIHEFE.

Viada, A. (1906, 12 de abril). Espíritu de clase. El Mundo Deportivo, p. 1.

Vilanou, C., y Martínez, A. (1995). Selección bibliográfica sobre Historia de la Educación Física. Historia de la Educación, 14 487-509. 


\section{Datos del autor}

Xavier Torrebadella Flix

Profesor Asociado. Universidad Autónoma de Barcelona. Facultad de Ciencias de la Educación. Departamento de Didáctica de la Expresión Musical, Plástica y Corporal.

xtorreba@gmail.com

Recibido - Received: 2016-05-08

Aceitado - Accepted: 2016-09-14

\section{(cc) BY}

This work is licensed under a Creative Commons Attribution 4.0 United States License.

\section{UILIS D-SulR}

This journal is published by the University Library System of the University of Pittsburgh as part of its D-Scribe Digital Publishing Program and is cosponsored by the University of Pittsburgh Press. 